
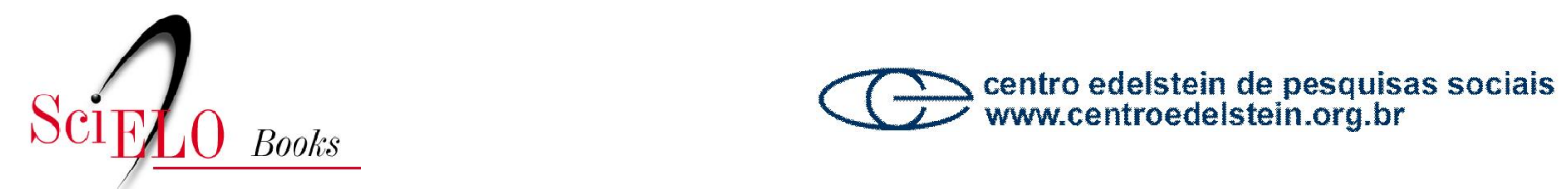

\title{
Nota sobre a pobreza rural
}

\author{
Juarez Rubens Brandão Lopes
}

SciELO Books / SciELO Livros / SciELO Libros

LOPES, JRB. Brasil, 1989: um estudo sócio-econômico da indigência e da pobreza [online]. Rio de Janeiro: Centro Edelstein de Pesquisas Sociais, 2008. Nota sobre a pobreza rural. pp. 53-58. ISBN: 978-85-99662-75-5. Available from SciELO Books $<$ http://books.scielo.org $>$.

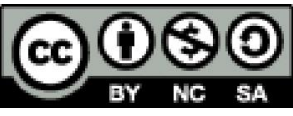

All the contents of this chapter, except where otherwise noted, is licensed under a Creative Commons Attribution-Non Commercial-ShareAlike 3.0 Unported.

Todo o conteúdo deste capítulo, exceto quando houver ressalva, é publicado sob a licença Creative Commons Atribuição Uso Não Comercial - Partilha nos Mesmos Termos 3.0 Não adaptada.

Todo el contenido de este capítulo, excepto donde se indique lo contrario, está bajo licencia de la licencia Creative Commons Reconocimento-NoComercial-CompartirIgual 3.0 Unported. 


\section{Nota sobre a pobreza rural}

O dimensionamento e a caracterização da pobreza rural no Brasil, pelo método das linhas de pobreza, com os dados de que se dispõe, são precários. Se é relativamente grosseira a extrapolação que fiz de linhas de pobreza para as regiões urbanas do Brasil, a partir daquelas estimadas por Sonia Rocha para as áreas metropolitanas, com muito maior razão qualquer cálculo semelhante feito para as áreas rurais é de valor ainda mais duvidoso. O que torna precários os resultados é o pressuposto de que os custos alimentares e custos totais nas zonas rurais tenham evoluído desde a época da realização do ENDEF (1974/5), no mesmo ritmo dos preços nas metrópoles (que foram os elementos usados por Sonia Rocha para atualizar os valores das linhas de pobreza metropolitanas).

Com esta advertência, apresento alguns dados sobre os pobres rurais, tanto a sua dimensão como as suas características. Antes porém, uma última reflexão. Suponho que as diferenças de custo de vida entre as metrópoles e as zonas rurais diminuíram, desde a realização do ENDEF, há mais de 15 anos atrás, principalmente nas regiões de agricultura mais moderna. Assim, as linhas de pobreza que usei ${ }^{33}$ são possivelmente baixas demais e subestimam a pobreza rural. Por outro lado, também é possível que as características 'pobres' encontradas, estejam mais acentuadas do que estariam, se as linhas traçadas fossem mais altas.

Dito tudo isto, passo aos dados. Estes indicam que perto de 3,2 milhões de domicílios rurais das regiões Nordeste, Sudeste e Sul acham-se em situação de pobreza (PNSN, 1989), quase 45 por cento do total dos domicílios rurais. Neles contam-se 17,3 milhões de pessoas, mais da metade da população rural ${ }^{34}$.

\footnotetext{
${ }^{33}$ Os valores que encontrei para as linhas de indigência (I) e pobreza (P) foram os seguintes (em dólares mensais):

Nordeste rural: 1 - $\$ 12,88, \mathrm{P}$ - $\$ 18,95$;

Sudeste rural: 1 - $\$ 13,11, \mathrm{P}-\$ 20,73$; e

Sul rural: 1 - $\$ 14,72, \mathrm{P}-\$ 23,74$.

Deixamos de lado a zona rural do Centro-Oeste, para a qual não havia elementos no ENDEF (apud Fava, 1984) para realizar a extrapolação necessária. Quando, portanto, nesta nota, falo de regiões rurais do Brasil, quero me referir apenas ao conjunto daquelas três regiões.

${ }^{34}$ Os dados correspondentes para os pobres indigentes ou miseráveis são: 1,9 milhões de domicílios (27\% do total) e 11 milhões de pessoas (um em cada três habitantes rurais).
} 
Para a caracterização dos pobres rurais, sempre em confronto com os pobres urbanos, restrinjo-me aos dados de duas tabelas. Uma apresenta a distribuição dos domicílios pobres segundo as suas estruturas familiares e a outra, dados sobre a habitação e suas posses, sobre características do chefe e do conjunto dos membros do domicílio, particularizando a sua situação de trabalho e renda.

A principal impressão que se fica do exame dos dados destas duas tabelas é a de que os pobres rurais, comparados com os urbanos, estão em grande proporção, numa mesma situação de pobreza. Em outras palavras, enquanto entre os pobres urbanos, pode-se discernir um certo número de situações diferenciadas, a pobreza rural é mais homogênea.

\section{Vejamos.}

Pela Tabela 21 verifica-se que a grande maioria dos domicílios pobres (80\%) tem estruturas familiares constituídas de casais e filhos (e mais, às vezes, algum outro parente), com chefe masculino (jovens, de meia-idade ou idosos), isto é, são dos tipos indicados na tabela pelos símbolos $\mathrm{C} 1, \mathrm{C} 2$ e $\mathrm{ID}^{35}$. No total da pobreza urbana, esses três tipos representam apenas $63 \%^{36}$

Isto decorre da alta probabilidade dos tipos $\mathrm{C} 1$ e $\mathrm{C} 2$ rurais serem pobres, e não da sua freqüência na população rural total. Por sua vez, os tipos de estrutura familiar com maior probabilidade de serem pobres no caso das regiões urbanas, são os pluri-familiares e os chefiados por mulheres (M1 e M2), tipos estes pouco freqüentes no meio rural.

A Tabela 22 mostra também, sobejamente, a menor heterogeneidade da pobreza rural.

\footnotetext{
35 O tipo ID1, como definido, pode ter chefia feminina. Entretanto, apenas $12 \%$ dos domicílios rurais pobres têm chefia feminina (comparados com $26 \%$ para os urbanos). Notese, além disso, que neste tipo o chefe pode já estar sozinho (viúvo).

${ }^{36}$ Sobre a distribuição dos domicílios urbanos segundo a estrutura familiar, consultar a Tabela 5 .
}

Tabela 21

Proporçăo de Domicilios Rurais Pobres e Probabilidade de Pobreza, Segundo a Estrutura Familiar, 1989

\begin{tabular}{cccccc}
\hline Estrutura & \multicolumn{4}{c}{ Domiclios Rurais (1) } & $\begin{array}{c}\text { Probabilidade } \\
\text { Familiar (2) }\end{array}$ \\
\cline { 2 - 5 } De Ser Pobre \\
\hline I & 1120 & 0.04 & 69443 & 0.98 & 1.61 \\
CO & 22762 & 0.72 & 165935 & 2.35 & 13.72 \\
C1 & 910945 & 28.70 & 1759627 & 24.88 & 51.77 \\
C2 & 1319957 & 41.59 & 2573113 & 36.38 & 51.30 \\
ID1 & 308413 & 9.72 & 771516 & 10.91 & 39.97 \\
ID2 & 113432 & 3.57 & 451023 & 6.38 & 25.15 \\
Outr & 88328 & 2.78 & 492404 & 6.96 & 17.94 \\
Pluri & 220015 & 6.93 & 459738 & 6.50 & 47.86 \\
& & & & & \\
M1 & 47089 & 1.48 & 60678 & 0.86 & 77.60 \\
M2 & 141834 & 4.47 & 269655 & 3.81 & 52.60 \\
& & & & & \\
\hline Total & 3173895 & 100.00 & 7073132 & 100.00 & 44.87
\end{tabular}

(1) Das regioes Nordeste, Sudeste e Sul.

(2) Ver nota de rodapé no 11.

(3) Exclusive os domiclilios com declaraç̧o de renda incompleta.

Fonte: PNSN, 1989

Quanto às condições habitacionais, particularmente aquelas que indicam má situação sanitária, elas são péssimas na grande maioria dos domicílios pobres rurais. Indicadores como ausência de esgoto e privada, disposição do lixo em terreno baldio (ou em 'outro' lugar) situam-se entre 70 e $80 \%$, ou no caso da 'rua de terra' atinge a totalidade dos pobres rurais $(98 \%)^{37}$. Para os domicílios pobres urbanos, os valores destes indicadores situam-se entre 11 (esgoto) e 58\% (rua de terra), indicando uma muito

${ }^{37}$ Todas estas estatísticas, e as que se seguem, discriminam bem, como no caso das regiões urbanas, pobres de não pobres rurais. 
maior heterogeneidade de situações da pobreza urbana.

O mesmo pode-se dizer dos indicadores de isolamento cultural. Nas zonas rurais, $61 \%$ dos chefes de domicílios pobres são analfabetos (junto com os que têm menos de 4 séries de escolaridade atinge-se 87\%), 80\% não têm livros em casa e $85 \%$ não têm TV; as porcentagens correspondentes para os pobres urbanos são, respectivamente, 33 (57\% com os que têm no máximo 3 séries concluídas), 56 e $35 \%$.
Tabela 22

Características dos Domicilios e de suas Posses, e do Trabalho e Renda dos Membros dos Domicilios e de seus Chefes, Pobres Rurais (1) e Urbanos, PNSN, 1989.

\begin{tabular}{|c|c|c|}
\hline \multirow{2}{*}{$\begin{array}{l}\text { Caracteristicas Selecionadas } \\
\text { Nåo tem Esgoto }\end{array}$} & \multicolumn{2}{|c|}{ Domicilios Pobres } \\
\hline & 70.73 & 10.64 \\
\hline Não tem Vaso Sanitário & 79.78 & 18.27 \\
\hline Lixo: Terreno Baldio ou 'Outro' Lugar & 69.75 & 26.41 \\
\hline Rua de Terra & 97.87 & 58.10 \\
\hline Domicilios Rústicos & 20.98 & 4.75 \\
\hline Paredes de Taipa ou 'Outro' Material & 26.02 & 5.69 \\
\hline Não tem Livros & 79.82 & 55.64 \\
\hline Não tem TV & 84.87 & 34.96 \\
\hline Chefe Preto ou Pardo & 68.17 & 60.37 \\
\hline Chefe Analfabeto & 60.56 & 32.95 \\
\hline Chefe com menos de 4 Séries Concluídas & 86.87 & 57.38 \\
\hline Chefes Mulheres & 11.88 & 26.05 \\
\hline Chefes com Ocupaçăo 'Pobre' (2) & 71.38 & 44.14 \\
\hline \multicolumn{3}{|l|}{ Chefe C. Própria/ Empregador/ N. Remunerado } \\
\hline Nåo Contribuinte & 93.48 & 77.11 \\
\hline Chefe Empregado sem Carteira & 73.92 & 37.87 \\
\hline Chefe Procurou Emprego Último Ano & 13.32 & 23.79 \\
\hline Membros Domicilio só tem Renda Trabalho & 66.48 & 52.03 \\
\hline Membros do Domicilio Segundo a Atividade & & 10.83 \\
\hline Todos Ocupados & 13.37 & 56.46 \\
\hline Ocupados e Inativos & 71.55 & 22.68 \\
\hline Um ou Mais Membro Desempregado. & 6.78 & 10.04 \\
\hline Todos Inativos & 8.30 & \\
\hline
\end{tabular}

(1) Das regizes Nordeste, Sudeste e Su

(2) Ver Anexo Metodologico.

Fonte: PNSN, 1989.

NEPP/UNICAMP, 1998

Finalmente, o trabalho e a renda, no caso dos pobres rurais, indicam também uma situação generalizada de completa dependência do trabalho, através de uma ocupação 'pobre', quase sem qualificação e sem garantias (carteira, previdência). A pobreza urbana, neste sentido também, aponta 
para situações bem mais diferenciadas. Tomemos um exemplo. Apenas 7\% dos domicílios pobres rurais têm algum membro desempregado e apenas $13 \%$ dos seus chefes informaram ter procurado trabalho nos últimos 12 meses (as porcentagens correspondentes para o meio urbano são, respectivamente, 23 e $24 \%$ ).

A situação no meio rural é menos uma questão de falta de emprego do que de misérrimos rendimentos (e, claro, maiores encargos familiares) e de insegurança no trabalho. Sessenta e seis por cento dos domicílios pobres rurais têm apenas rendas do trabalho (52\% dos domicílios pobres urbanos), $71 \%$ dos seus chefes têm ocupações 'pobres' (44\% dos urbanos). Quase três quartos dos empregados pobres no meio rural não têm carteira de trabalho assinada e quase a totalidade (93\%) dos que trabalham por conta própria não contribuem para a previdência, o que mostra a "informalidade" das situações de trabalho (nas regiões urbanas aquelas porcentagens são 38 e $77 \%)$.

Entretanto, volto à minha ressalva inicial. Embora trate-se de proporções altas da população rural total, é possível que este conjunto de domicílios pobres que isolamos, devido às estimativas baixas das linhas de pobreza, não constitua a totalidade dos pobres que realmente existem ${ }^{38}$. Neste caso, o grau de homogeneidade da pobreza rural seria talvez menor, como também menores seriam as diferenciações rural-urbanas que sublinhamos.

\footnotetext{
${ }^{38}$ No sentido de sua renda per capita não alcançar o custo de vida médio necessário (custos alimentares e não alimentares) realmente prevalecente (ver o item "Linhas de Indigência e de Pobreza", do Anexo Metodológico).
} 